\title{
Retrospective Study of Fishery Interactions in Stranded Cetaceans, Canary Islands
}

\author{
Raquel Puig-Lozano ${ }^{1}$, Antonio Fernández ${ }^{1}$, Eva Sierra ${ }^{1}$, Pedro Saavedra ${ }^{2}$, \\ Cristian M. Suárez-Santana ${ }^{1}$, Jesús De la Fuente ${ }^{1}$, Josué Díaz-Delgado ${ }^{3}$, Ana Godinho ${ }^{4,5}$, \\ Natalia García-Álvarez ${ }^{1}$, Daniele Zucca ${ }^{1}$, Aina Xuriach ${ }^{1}$, Marina Arregui ${ }^{1}$, \\ Idaira Felipe-Jiménez ${ }^{1}$, Francesco Consoli ${ }^{1}$, Pablo J. Díaz-Santana ${ }^{1}$, \\ Simone Segura-Göthlin ${ }^{1}$, Nakita Câmara ${ }^{1}$, Miguel A. Rivero ${ }^{1}$, Simona Sacchini ${ }^{1}$, \\ Yara Bernaldo de Quirós ${ }^{*}$ and Manuel Arbelo ${ }^{1}$
}

${ }^{1}$ Veterinary Histology and Pathology, Atlantic Center for Cetacean Research, University Institute of Animal Health and Food Safety (IUSA), Veterinary School, University of Las Palmas de Gran Canaria, Las Palmas of Gran Canaria, Spain, ${ }^{2}$ Department of Mathematics, University of Las Palmas de Gran Canaria, Las Palmas of Gran Canaria, Spain, ${ }^{3}$ TVMDL Texas A\&M, Veterinary Medical Diagnostic Laboratory, College Station, TX, United States, ${ }^{4}$ Life and Health Sciences Research Institute (ICVS), School of Medicine, University of Minho, Braga, Portugal, ${ }^{5}$ ICVS/3B's - PT Government Associate Laboratory, Braga/Guimarães, Portugal

Edited by:

Robert James Ossiboff, University of Florida, United States

Reviewed by:

Graham Pierce,

Higher Council for Scientific Research (CSIC), Spain Valentín Pérez,

Universidad de León, Spain

*Correspondence: Yara Bernaldo de Quirós yara.bernaldo@ulpgc.es

Specialty section: This article was submitted to Veterinary Experimental and

Diagnostic Pathology,

a section of the journal

Frontiers in Veterinary Science

Received: 29 May 2020 Accepted: 01 September 2020 Published: 21 October 2020

Citation:

Puig-Lozano R, Fernández A, Sierra E, Saavedra P, Suárez-Santana CM, De la Fuente J, Díaz-Delgado J, Godinho A, García-Álvarez N, Zucca D, Xuriach A, Arregui M,

Felipe-Jiménez I, Consoli F, Díaz-Santana PJ, Segura-Göthlin S, Câmara N, Rivero MA, Sacchini S, Bernaldo de Quirós Y and Arbelo M (2020) Retrospective Study of Fishery Interactions in Stranded Cetaceans, Canary Islands.

Front. Vet. Sci. 7:567258 doi: 10.3389/fvets.2020.567258
Estimating cetacean interactions with fishery activities is challenging. Bycatch and chronic entanglements are responsible for thousands of cetacean deaths per year globally. This study represents the first systematic approach to the postmortem investigation of fishery interactions in stranded cetaceans in the Canary Islands. We retrospectively studied 586 cases necropsied between January 2000 and December 2018. Of the cases with a known cause of death, 7.4\% (32/453) were due to fishery interactions, and the Atlantic spotted dolphin (Stenella frontalis) was the most affected species [46.9\% (15/32)]. Three types of fishery interactions were recognized by gross findings: bycatch [65.6\% (21/32)], chronic entanglements [18.8\% (6/32)], and fishermen aggression [15.6\% (5/32)]. Among the bycaught cases, we differentiated the dolphins because of fishing net entrapments [76.2\% (16/21)], including dolphins that presumably died at depth due to peracute underwater entrapment (PUE) [37.5\% (6/16)], dolphins that were hauled out alive and suffered additional trauma during handling [43.8\% (7/16)], and those that were released alive but became stranded and died because of fishery interactions [18.7\% (3/16)]. Gross and histologic findings of animals in each group were presented and compared. The histological approach confirmed gross lesions and excluded other possible causes of death. Cetaceans in good-fair body condition and shallow diving species were significantly more affected by fishery interactions, in agreement with the literature. Low rates of fishery interactions have been described, compared with other regions. However, within the last few years, sightings of entangled live whales, especially the minke whale (Balaenoptera acutorostrata) and Bryde's whale (B. edeni), have increased. This study contributes to further improvement of the evaluation of different types of fishery interactions and may facilitate the enforcement of future conservation policies to preserve cetacean populations in the Canary Islands.

Keywords: fisherman aggressions, peracute underwater entrapment, entanglement, bycatch, Bryde's whale, Atlantic spotted dolphin, longline hooks, minke whale that died because of ingestion of longline hooks [23.8\% (5/21)] from those that died 


\section{INTRODUCTION}

Fishery activities are a major threat to cetacean populations globally (1). Bycatch is a major cause of mortality and poses the highest widespread risk $(2,3)$. Detection of bycatch among cetaceans is challenging, as there are typically no pathognomonic lesions $(4,5)$.

Bycaught dolphins in gillnets or trawls are often reportedly healthy individuals in good body condition, with pathological findings that are usually consistent with peracute underwater entrapment (PUE) (5). The most common findings in this type of bycatch are net cuts and impressions on the skin (mainly over the head, but also affecting the flippers and body), changes in the lung (edema, multifocal emphysema, and atelectasis), recently ingested food, reddish or bulging eyes, congestion, and disseminated gas bubbles (6). Other bycatch findings include those produced by fishermen, such as gunshots, stabs over the body, or amputations to disentangle the animal from fishing nets, and abdominal cuts to sink the carcasses $(5,7)$. To identify bycatch as a cause of death, it is essential to rule out other possible causes of death.

Another type of fishery interaction is chronic entanglement with an active net, or with abandoned, lost or otherwise discarded fishing gear, which form part of the marine debris, and cause ongoing "ghost-fishing" for years $(8,9)$. At least 14 cetacean species have been reportedly entangled, and $97 \%$ of the cases were attached to fishing gear (10). Entanglements are considered a global threat, which international entanglement response and monitoring programs urge (11).

The Canary Islands are located in the region of Macaronesia, close to the north-western coast of Africa. With up to 30 cetacean species (Biocan-Banco del Inventario Natural de Canarias ${ }^{1}$, seven mysticetes and 23 odontocetes, the Canary Islands hold the greatest cetacean biodiversity among European territories, and its fisheries are mainly artisanal. The Atlantic Center for Cetacean Research has been monitoring the health of freeranging cetaceans stranded in the Canary Islands over the last 20 years. The three most stranded species are the Atlantic spotted dolphin (Stenella frontalis), the short-beaked common dolphin (Delphinus delphis), and the striped dolphin (Stenella coeruleoalba) $(12,13)$.

The aim of this study was to retrospectively investigate the prevalence and most common pathological findings of each type of fishery interaction, among stranded cetaceans in the Canary Islands. Our results will likely aid the promotion of adequate conservation policies in the archipelago and improve detection of this anthropic threat.

\section{MATERIALS AND METHODS}

Postmortem examinations of 586 cetaceans stranded along the coasts of the Canary Islands were performed from January 2000 to December 2018, following standardized protocols (14). No experiments were performed on live animals. Permission for

${ }^{1}$ https://www.biodiversidadcanarias.es/ the handling of stranded cetaceans was granted by the Spanish Ministry of Environment.

For each necropsied cetacean, the epidemiology of the stranding (i.e., location and date); life history data (i.e., species, growth development, sex, and gonad maturation); body condition; and decomposition code, were systematically recorded. Growth development categories (neonate, calf, juvenile, subadult, and adult) were extrapolated from the osteological characteristics of stranded cetaceans in the Canary Islands (15). Gonad maturation was determined, based on histological gonadal examination (16). Body condition (very poor, poor, fair, or good) was estimated, based on anatomical landmarks (17). The decomposition code (1-very fresh, 2fresh, 3-moderate autolysis, 4-advanced autolysis, and 5-very advanced autolysis) was determined following the classification of IJsseldijk et al. (18). During the necropsy, lesions were described and photographed. In one animal (case 26), the gas score was determined and gas analysis was performed following standardized protocols $(19,20)$. Representative tissue samples were fixed in $10 \%$ neutral buffered formalin, routinely processed, embedded in paraffin, sectioned at thickness of $5 \mu \mathrm{m}$, and stained with hematoxylin and eosin for histopathologic analysis.

A conservative approach was adopted to determine fishery interactions, based on previous studies $(5-7,12,13,21-$ 24). All stranding cases were reviewed retrospectively, as we looked for individuals with findings that were consistent with fishery interactions, and excluded cases in which other possible traumatic etiologies, such as ship collision, intra-interspecific interactions, or live stranding, could not have been ruled out (25-32). Different types of fishery interactions were determined based on gross findings. Within these various types, histological findings in the skeletal and cardiac muscle, lungs, liver, kidneys, brain, and adrenal glands of the cases with decomposition codes $1-3$, were detailed and compared, based on the availability of the samples.

In order to identify factors related to fishery interactions, categorical variables (species, sex, growth development, gonad maturation, body condition, diving behavior, island, and date of stranding) were expressed as frequencies and percentages, and were compared, as appropriate, using the chi-squared $\left(\chi^{2}\right)$ test or the Fisher's exact test. Fishing deaths were due to all of the different types of fishery interactions identified: chronic entanglements, fishermen aggressions from the boat, and bycatch (including fishing net entrapments and ingestion of longline hooks). For statistical analyses, some categorical variables were further regrouped as follows: growth development category (neonate/calf, juvenile/subadult, and adult); body condition (very poor/poor and fair/good); and stranding island based on geographical proximities and the presence of high-site fidelity populations [Western Islands (El Hierro and La Palma), La Gomera together with Tenerife, Gran Canaria, and Eastern Islands (Fuerteventura-Lanzarote-La Graciosa)]. All statistical analyses were performed only on those animals with an identifiable cause of death (453/586). Statistical significance was set at $p<0.05$. Data were analyzed using the $\mathrm{R}$ package, version 3.6.1 (33). 
TABLE 1 | Gross findings in stranded cetaceans, which died because of fishery interactions (chronic entanglement, aggression, or bycatch) ( $n=32)$.

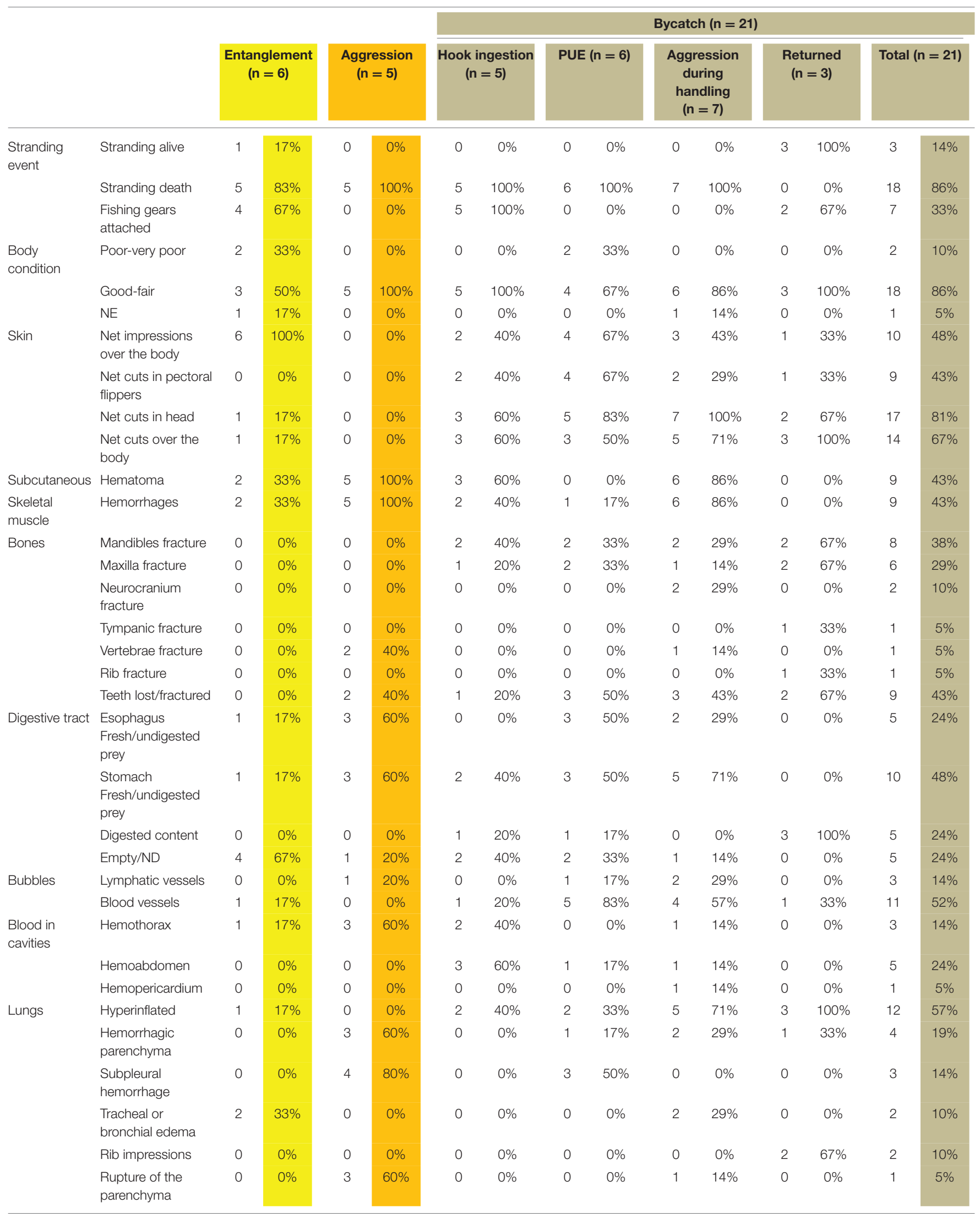




\begin{tabular}{|c|c|c|c|c|c|c|c|c|c|c|c|c|c|c|c|}
\hline \multirow[b]{2}{*}{ Heart } & \multirow[b]{2}{*}{ Hemopericardium } & \multicolumn{2}{|c|}{$\begin{array}{l}\text { Entanglement } \\
(n=6)\end{array}$} & & & & & & & Syca & (n $=2$ & & & & \\
\hline & & 0 & $0 \%$ & 0 & $0 \%$ & 1 & $20 \%$ & 0 & $0 \%$ & 0 & $0 \%$ & 0 & $0 \%$ & 1 & $5 \%$ \\
\hline \multirow[t]{2}{*}{ Large vessels } & $\begin{array}{l}\text { Aorta vascular } \\
\text { changes }\end{array}$ & 1 & $17 \%$ & 0 & $0 \%$ & 1 & $20 \%$ & 1 & $17 \%$ & 4 & $57 \%$ & 0 & $0 \%$ & 6 & $29 \%$ \\
\hline & $\begin{array}{l}\text { Rete mirabile } \\
\text { vascular changes }\end{array}$ & 0 & $0 \%$ & 0 & $0 \%$ & 0 & $0 \%$ & 0 & $0 \%$ & 2 & $29 \%$ & 0 & $0 \%$ & 2 & $10 \%$ \\
\hline Kidney & Hemorrhages & 0 & $0 \%$ & 0 & $0 \%$ & 0 & $0 \%$ & 0 & $0 \%$ & 1 & $14 \%$ & 0 & $0 \%$ & 1 & $5 \%$ \\
\hline \multirow[t]{2}{*}{ Brain } & $\begin{array}{l}\text { Meningeal } \\
\text { hemorrhages }\end{array}$ & 0 & $0 \%$ & 1 & $20 \%$ & 0 & $0 \%$ & 0 & $0 \%$ & 3 & $43 \%$ & 0 & $0 \%$ & 3 & $14 \%$ \\
\hline & $\begin{array}{l}\text { Parenchymal } \\
\text { hemorrhages }\end{array}$ & 0 & $0 \%$ & 0 & $0 \%$ & 0 & $0 \%$ & 0 & $0 \%$ & 1 & $14 \%$ & 0 & $0 \%$ & 1 & $5 \%$ \\
\hline
\end{tabular}

Decomposition codes (1-5). For each category, the number and percentage of affected individuals are shown.

The color values correspond to the percentage of a finding or a pathologic feature within each group of studied animals (bycatch, fisherman aggression and chronic entanglement).

\section{RESULTS}

A total of 860 cetaceans were stranded along the coasts of the Canary Islands between January 2000 and December 2018. Among them, 586 cetaceans were necropsied. The full anatomopathological study of each case allowed us to identify the most probable cause of death in 453 cases. Of those cases, 32 (7.4\%) cetaceans of seven species died because of the pathological consequences of fishery interactions.

\section{Types of Fishery Interactions}

Cases of fishery interactions $(n=32)$ were divided into three categories: bycatch (i.e., longline hook ingestion or fishing net entrapment) $(n=21)$; chronic entanglements $(n=6)$; and fisherman aggressions $(n=5)$ (Supplementary Table 1).

\section{Bycatch}

The bycatch group included cetaceans that were presumably entrapped in active fishing gear. In this group $(n=21)$, four species were affected: the Atlantic spotted dolphin $(n=12)$; striped dolphin $(n=6)$; common dolphin $(n=2)$; and Atlantic bottlenose dolphin (Tursiops truncatus) $(n=1)$. All growth development categories were affected by bycatch. The adults were the most affected $(11 / 21)$, followed by the juveniles $(6 / 21)$, subadults $(3 / 21)$, and calves $(2 / 21)$.

This group was further divided into the following subgroups: dolphins that ingested longline hooks (5/21); dolphins with lesions compatible with forced submersion, which presumably died at depth due to PUE (6/21); dolphins that were stranded alive and later died, exhibiting lesions that were consistent with
PUE (3/21); and polytraumatized dolphins that were hauled out alive but suffered additional trauma during handling, including mainly cranioencephalic trauma, and/or perforations produced by fishing equipment (7/21).

Different degrees of chronicity of the lesions were observed; from acute lesions in PUE cases to subacute-chronic lesions in cases of longline hook ingestion. However, some gross findings were common among most cases (Table 1). Almost every bycaught case showed fair to good body condition. In addition, many animals exhibited superficial cutaneous lesions caused by contact with fishing nets, mainly on the rostrum, but also on the flippers, and along the sides of the body, as well as net impressions (Figures 1A,B). Other common findings included diffuse bilateral hyperinflated lungs (Figure 1C, inset upper image), disseminated intravascular gas bubbles in the veins and lymphatic vessels (Figures 1D,E). In fewer cases, undigested food was found in the forestomach (Figure 1C inset lower image), occasionally in the esophagus, and/or associated with the presence of abundant lymph in the lymphatic mesenteric vessels and chyle in the thoracic duct. Lost teeth (Figure 1F), a fractured rostrum and/or maxilla, and retroperitoneal emphysema were also described. Gross findings of each bycatch case are presented in Supplementary Table 2.

Histologically, almost all cases showed clear intravascular spaces compatible with gas and/or fat embolism. Common findings included: mild to moderate multifocal acute degenerative changes in skeletal muscle (i.e., segmental degeneration of the muscular fibers); mild multifocal acute degenerative changes in cardiac muscle (i.e., increased acidophilic cytoplasm of the myocardiocytes, contraction 

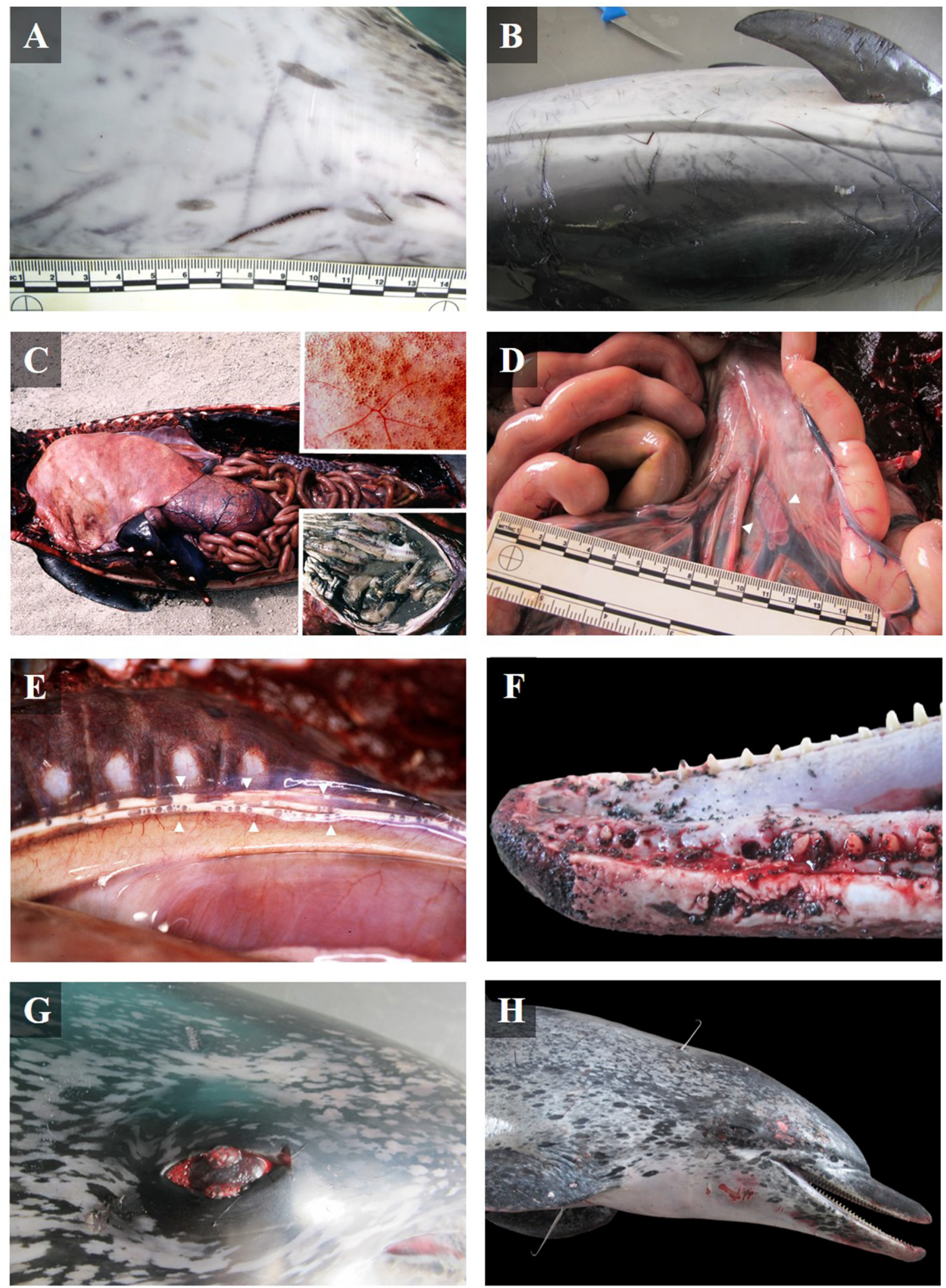

FIGURE 1 | Gross lesions in bycaught dolphins stranded along the Canary Islands. (A) Cutaneous impressions presumably produced by a twisted wire net, and (B) linear and typical triangular monofilament cuts on an adult Atlantic spotted dolphin (case 29). (C) Left lateral view of the thoracic and abdominal cavities of a juvenile 
FIGURE 1 | Atlantic bottlenose dolphin (case 7). Severe hyperinflated lungs with emphysema (inset upper image), and full stomach with undigested food, fresh fish (inset lower image). (D) Mesenteric veins with severe multifocal intravascular gas bubbles in an adult common dolphin (case 32). (E) Thoracic duct (between arrow points) full of lymph and gas bubbles in an Atlantic spotted dolphin calf (case 1). (F) Left lateral view of the rostrum with multifocal fracture and lost teeth in the rostral part of the mandible (case 21). (G) Reddish eyes with conjunctival emphysema of an adult Atlantic spotted dolphin, found with an ingested longline hook (case 29). (H) Right lateral view of an adult Atlantic spotted dolphin with two perforating thoracic wounds. The tracks of the wounds, marked by two steel skewers, probably produced during aggressive handling (case 21).

band necrosis, and juxtanuclear vacuolization of cardiac cells); multifocal lung changes such as alveolar emphysema, hemorrhages, and alveolar edema; systemic leukocytosis; and multifocal intracytoplasmic hepatocellular hyaline globules. In fewer cases, bronchiolar sphincter contraction, multifocal hyaline casts in distal renal tubules and corticomedullary adrenal hemorrhages, intramuscular hemorrhages, and multifocal pigmentary tubulonephrosis were observed. Regarding the central nervous system (CNS), mild changes manifested as multifocal hemorrhages, perivascular edema, and perivascular cuffs mostly associated with glial nodules were observed in a few cases. A severe non-suppurative meningoencephalitis was present in one case (Table 2). Histological findings of each bycatch case are presented in Supplementary Table 3.

All animals affected by the ingestion of longline hooks ( $n$ $=5$ ) were adult Atlantic spotted dolphins in fair-good body condition. Ingested hooks had perforated the esophagus (cases 2 and 29), produced fibrinosuppurative pleuritis and pericardial hemorrhages (case 29; Figure 2D), pierced the mandibular fossa (cases 18 and 31 ), and affected the sublingual soft tissue to produce focal, extensive necrosis and hemorrhage (case 20). Hemothorax, hemoabdomen, and hemopericardium were also observed (Table 1). In one case, reddened eyes were observed (Figure 1G).

Of the six cases showing findings consistent with PUE, four were striped dolphins [one pregnant adult (case 17), two subadults (cases 28 and 30), and one juvenile (case 25)]; one was a Atlantic spotted dolphin calf (case 1); and another, a juvenile Atlantic bottlenose dolphin (case 7). All animals in this category were found dead, and the majority were in good-fair body condition. All had cutaneous lesions associated with contact with fishing nets, as well as disseminated intravascular gas bubbles, cutaneous impressions, lost/fractured teeth, undigested food, hyperinflated lungs with subpleural hemorrhages and hemorrhagic parenchyma, and retroperitoneal emphysema (Table 1).

Three other animals showed lesions compatible with PUE. They were likely caught in nets and released alive back into the ocean. They included a striped dolphin calf (case 6), a juvenile striped dolphin entangled in gear with a fishing ball (case 12), and an adult Atlantic spotted dolphin that appeared to have been entangled in a fishing net (case 23). Supposedly, shortly after release, these animals were stranded alive and subsequently died. Two had fractured bones [mandible and maxilla with lost or fractured teeth, tympanic fracture, and rib fracture], which may have been caused by active stranding (Table 1). Disseminated intravascular gas bubbles were present in case 23 alone. The same animal had bubbles within the posterior chamber of the eye.
Bycaught cases included seven animals that were probably hauled out and raised to the deck alive but suffered different forms of physical trauma during handling. The affected cases included Atlantic spotted dolphins $(n=5)$ [three adults (cases 11,21 , and 22); one subadult (case 27); and one juvenile (case $9)$ ], and common dolphins $(n=2)$ [one adult (case 32) and one juvenile (case 26)]. All were stranded dead, and most were in fair body condition. These animals were polytraumatized and exhibited skin-muscle perforations (Figure 1H) with associated hemorrhages, which affected internal organs in some cases [perforations of the aorta (case 9), trachea and esophagus (case 22)]; neurocranium fractures (2/7) [in the squamous part of the occipital bone (case 27), and in the right occipital condyle (case 32)] with associated hematoma and congestion in the underlying leptomeninges and brain; and fractures of the maxilla and mandible (cases 26 and 32). Case 26 also showed signs of severe trauma to the right caudolateral side of the head with leptomeningeal congestion, severe scoliosis of the peduncle, and an open fracture that affected the caudal vertebrae. Other traumatic findings included hemorrhages on the adventitia of the aorta (cases 9, 11, 22, and 26) and in the rete mirabile (cases 22 and 26); hemothorax (cases 11 and 22); hemoabdomen (case 22 ); hemopericardium (case 22); and lung perforation (case 11) (Table 1).

Disseminated intravascular gas bubbles were present in four out of seven bycaught animals. One was a juvenile female common dolphin (case 26) that was found stranded dead, refrigerated $\left(4^{\circ} \mathrm{C}\right)$ for $24 \mathrm{~h}$, and necropsied while still fresh (decomposition code 2). The gas score and gas analyses were evaluated on this animal. The gas score revealed the presence of occasional small bubbles following careful screening of the subcutaneous veins (gas score 1); abundant presence of gas bubbles in the coronary veins and lumbocaudal venous plexus (gas score 5); and gas bubbles occupying complete sections of the mesenteric veins (gas score 6). Emphysema was present exclusively in the perirenal subcapsular region.

Gas analyses were performed in mesenteric veins, the right ventricle, aorta, pulmonary artery, and intestinal lumen (Figure 3). Except for samples of the intestine and mesenteric veins, $\mathrm{N}_{2}$ was the main component of the sampled bubbles [61.0 $\pm 9.2 \mu \mathrm{mol} \%$, followed by $\mathrm{CO}_{2}[30.0 \pm 16.2 \mu \mathrm{mol} \%]$, and $\mathrm{O}_{2}[8.9 \pm 7.1 \mu \mathrm{mol} \%]$. Both $\mathrm{CH}_{4}$ and $\mathrm{H}_{2}$ were absent from these samples. In contrast, gas bubbles from the mesenteric veins contained $\mathrm{H}_{2}$ [31.2 $\left.\pm 10.2 \mu \mathrm{mol} \%\right]$, in addition to $\mathrm{N}_{2}[54.8 \pm$ $3.7 \mu \mathrm{mol} \%], \mathrm{O}_{2}[11.6 \pm 3.2 \mu \mathrm{mol} \%]$, and $\mathrm{CO}_{2}[2.4 \pm 3.3 \mu \mathrm{mol}$ $\%$ ]. In the intestinal lumen, $\mathrm{CO}_{2}$ was the main constituent [78.4 $\pm 2 \mu \mathrm{mol} \%$, followed by $\mathrm{H}_{2}[16.4 \pm 1.3 \mu \mathrm{mol} \%], \mathrm{N}_{2}$ [4.2 \pm 2.6 $\mu \mathrm{mol} \%]$, and $\mathrm{O}_{2}[1 \pm 0.5 \mu \mathrm{mol} \%]$. 
TABLE 2 | Histological findings in stranded cetaceans, which died because of fishery interactions.

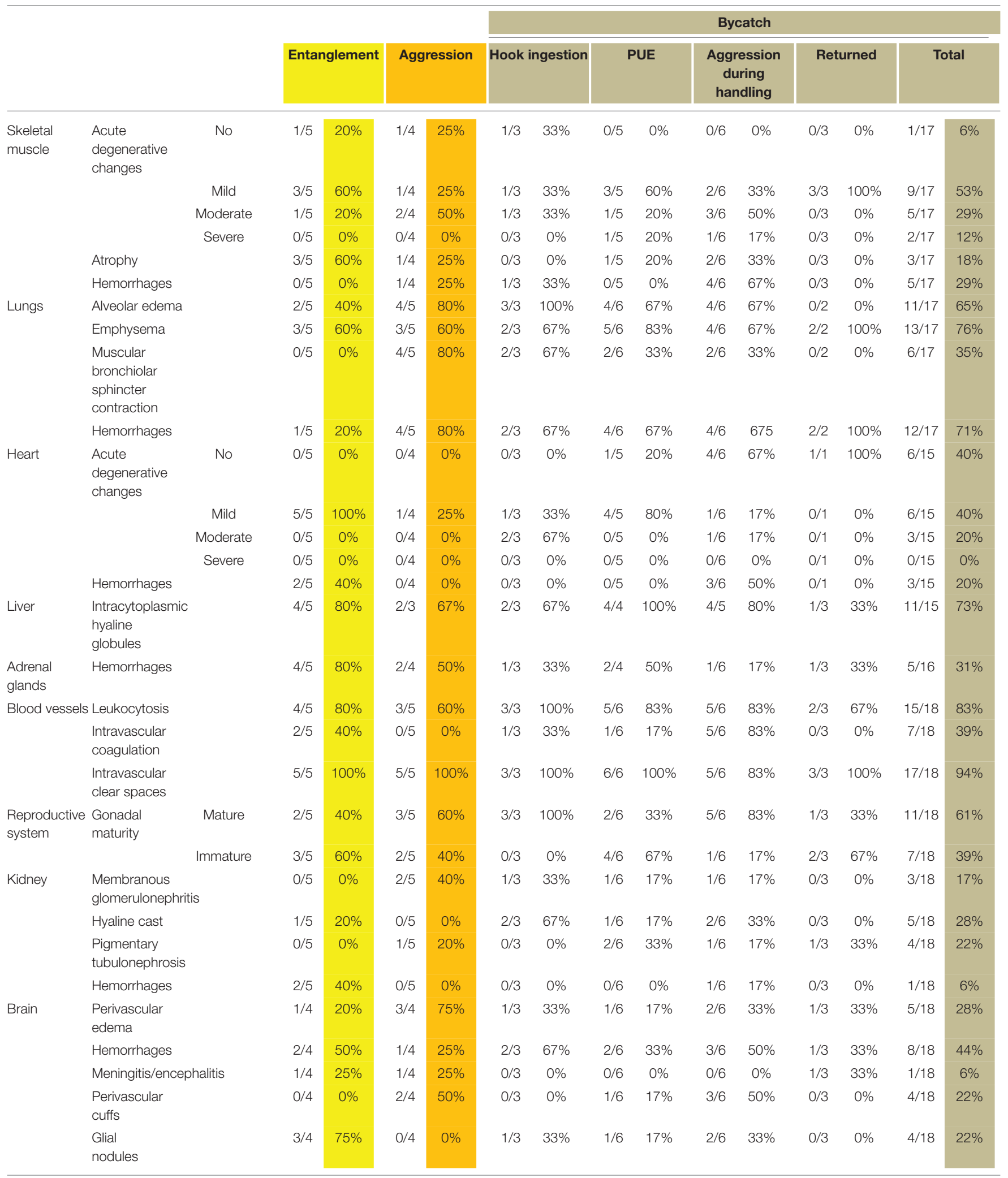

For cases with decomposition codes 1-3 ( $n=28)$, histological findings in the skeletal and cardiac muscle, lungs, liver, kidneys, adrenal glands, blood vessels, and brain, were detailed and compared, as well as findings of gonad maturation ( $M$, mature; I, immature) upon the availability of samples.

The color values correspond to the percentage of a finding or a pathologic feature within each group of studied animals (bycatch, fisherman aggression and chronic entanglement). 

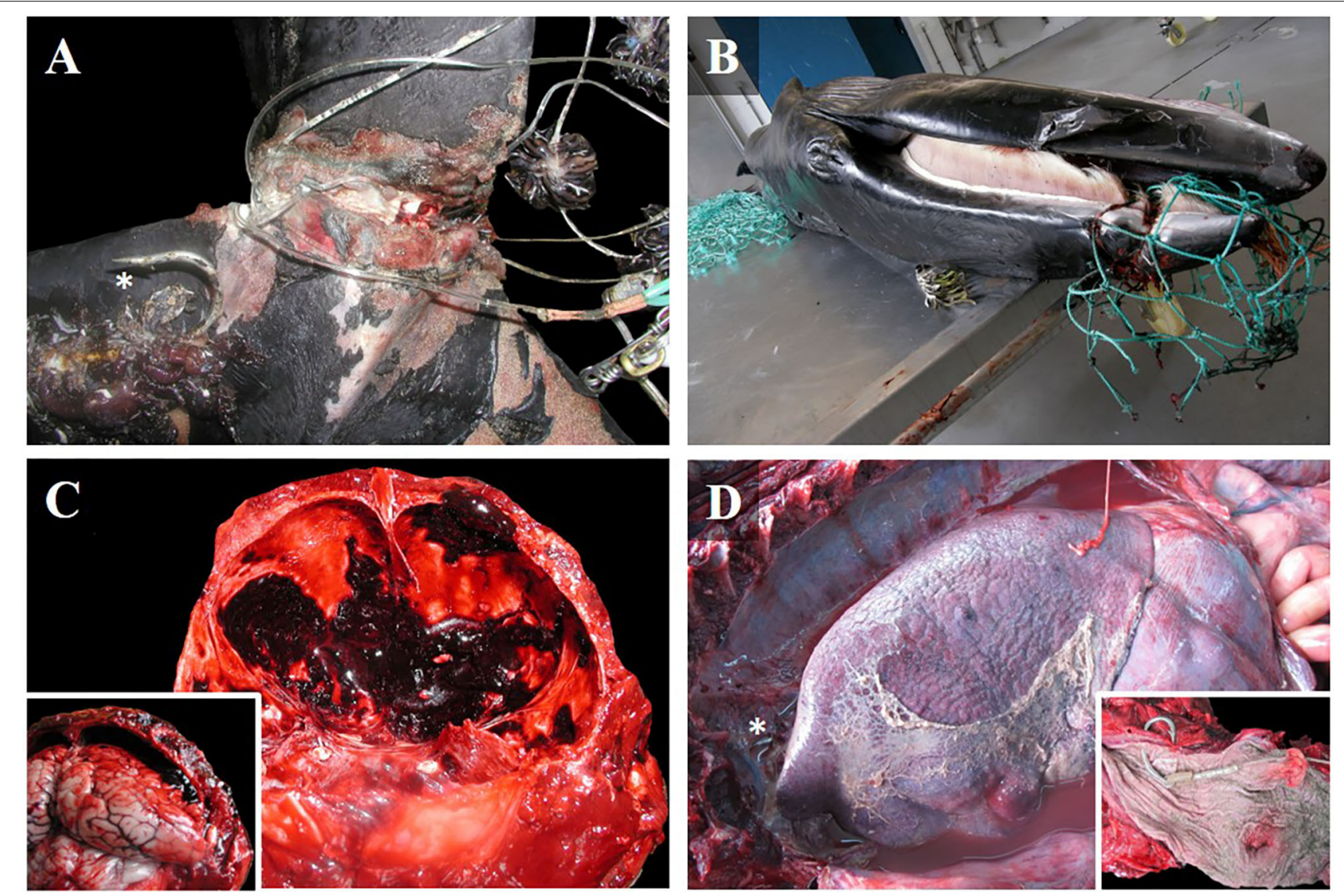

FIGURE 2 | Gross findings in cetacean deaths caused by different types of fishing interactions. (A) Dorsal view of the caudal peduncle of a Gervais' beaked whale calf (case 10), entangled in a longline. Cirripeds and a hook (asterisk) were attached to the nylon wire. Severe chronic skin ulcerations were observed, with a loss of soft tissue, and granulation tissue on the borders of the wound. Note that the fluke was almost amputated. (B) Lateral view of entangled minke whale calf (case 16) with chronic ulcerative stomatitis affecting the maxilla, and tissue strangulation. (C) Caudal view of the cranium of an adult Atlantic spotted dolphin (case 13) with a fatal subdural hematoma, and associated brain compression (inset). (D) Left lateral view of the thoracic cavity of an adult Atlantic spotted dolphin (case 29). Fibrinosuppurative pleuritis and pyothorax caused by ingestion of a longline hook (asterisk) that perforated the thoracic portion of the esophagus (inset).

\section{Chronic Entanglement}

In this category, we observed six cases with skin wounds that were consistent with chronic entanglement. They included two minke whale calves (Balaenoptera acutorostrata) (cases 16 and 19); two short-finned pilot whale calves (Globicephala macrorhynchus) (cases 14 and 24); one Gervais' beaked whale calf (Mesoplodon europaeus) (case 10); and one subadult Atlantic bottlenose dolphin (case 8). Regarding body condition, three out of six cases showed fair to good body condition (cases 8, 14, and 19), while two were in poor-very poor condition (cases 10 and 16). In case 24, the advanced decomposition (code 5) did not allow us to determine the body condition, nor perform histological evaluation.

All cases exhibited fishing gear impressions, erosions, and/or ulcerative lesions with granulation tissue and fibrosis over the rostrum, flippers, and/or tail. In case 14, the animal was stranded alive with nylon wire attached to a plastic floating bottle. The other five were found dead. Case 8 exhibited rope impressions between the pectoral fins and near the left eye.
In case 10 , nylon wire with cirripeds and longline hooks were attached to the caudal peduncle (Figure 2A). Case 16 had green monofilament nylon fishing gear attached to the maxilla (Figure 2B). Case 19 exhibited symmetrical bilateral ulcers and granulation tissue in the mandibular symphysis, consistent with fishing gear impressions. Case 24 had a thick rope $(4 \mathrm{~cm}$ in diameter) surrounding the thoracic region. Other pathological findings included tracheal edema, hyperinflated lungs with rib impressions, serous atrophy of pericardial fat, hemorrhage in the adventitia of the thoracic aorta, and retroperitoneal emphysema. Only two cases had undigested food in the stomach (Table 1). Gross findings of each case are presented in Supplementary Table 2.

Histologically, clear intravascular spaces, compatible with intravascular gas and/or fat, mild to moderate multifocal acute muscular degenerative changes in skeletal muscle, and mild degenerative changes in the cardiac muscle, multifocal myofiber atrophy of the skeletal muscle, multifocal corticomedullary adrenal hemorrhages, intracytoplasmic hepatocellular hyaline 


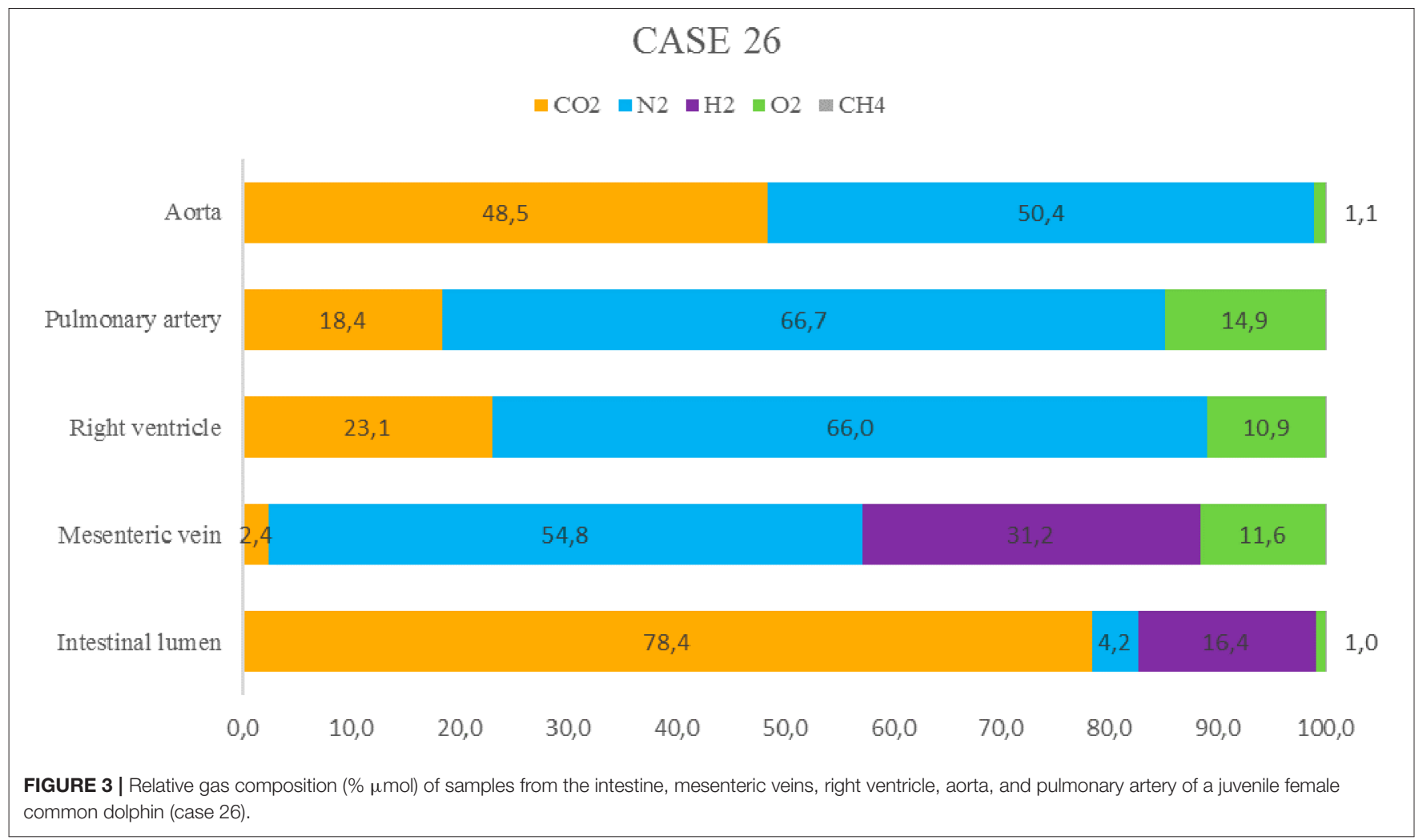

globules, systemic leukocytosis, hemorrhages in multiple organs, intravascular coagulation, multifocal alveolar emphysema, alveolar edema, diffuse hemorrhagic lung parenchyma, multifocal hemorrhages in the cortex of the kidney, and hyaline casts were observed. Regarding the CNS, case 8 showed mild focal non-suppurative meningoencephalitis. Mild multifocal glial nodules and moderate multifocal hemorrhages were occasionally observed (Table 2). Histological findings are presented in Supplementary Table 3.

\section{Fisherman Aggression}

In this category $(n=5)$, we observed three Atlantic spotted dolphins [two adults (cases 3 and 13) and one juvenile (case 15)], and two common dolphins [one adult and one calf, possibly relatives as they were stranded on the same date and location (cases 4 and 5)]. All cetaceans in this group showed fair-good body condition, and a full stomach with undigested prey, as well as signs of anthropogenic trauma, such as unique or multifocal stabs inflicted by sharp instruments, mainly in the laterodorsal area affecting the thoracic region (cases 3, 4, 5, and 15) and dorsal side of the head (cases 3 and 13). Net cuts and impressions were not observed on the skin (Table 1). These animals exhibited several lesions associated with incisive trauma, such as vascular changes (i.e., edema, hemorrhage, hematoma) in the skin and muscular tissue, bone fractures [sixth left rib (case 4) and the ninth thoracic vertebrae (case 5)], lung perforations with related focal, extensive hemorrhage, and hemothorax (cases 4, 5, and 15), and hemorrhage in the leptomeninges (case 13; Figure 2C) were observed (Table 1). Gross findings of each case are presented in Supplementary Table 2 .

Histologically, mild to moderate multifocal acute segmental myofiber degeneration of skeletal muscle, diffuse hemorrhages within the affected skin and muscles, mild multifocal acute degenerative changes in cardiac muscle, multifocal alveolar edema, hemorrhages in the lung parenchyma, muscular sphincter contraction of the bronchioles, multifocal emphysema, systemic leukocytosis, intracytoplasmic hepatocellular hyaline globules, multifocal corticomedullary adrenal gland hemorrhages, multifocal membranous glomerulonephritis, and multifocal pigmentary tubulonephrosis were observed. Regarding the CNS, multifocal perivascular edema, perivascular cuffs, and hemorrhages in the brain parenchyma were occasionally observed. Mild multifocal granulomatous encephalitis was present in case 3. Clear intravascular spaces were present in all cases (Table 2). Histological findings are presented in Supplementary Table 3.

\section{Statistical Analysis}

Although almost half of the affected animals were Atlantic spotted dolphins [46.9\% (15/32)], no statistically significant differences were found in the prevalence of fishery interactions among animals of different species $(p=0.125)$, nor among growth development categories $(p=0.871)$, sex $(p=0.813)$, gonad maturation $(p=0.704)$, or the island of stranding ( $p=$ 0.684) (Table 3). 
TABLE 3 | Statistical analysis of the epidemiological data of studied cetaceans during the period 2000-2018 ( $n=586)$.

\begin{tabular}{|c|c|c|c|c|}
\hline & $\begin{array}{r}\text { Overall } \\
\mathrm{N}=586\end{array}$ & $\begin{array}{c}\text { Other cause of } \\
\begin{array}{c}\text { death } \\
N=421\end{array}\end{array}$ & $\begin{array}{l}\text { Fishing interactions } \\
\qquad N=32\end{array}$ & P-value \\
\hline Balaenoptera acutorostrata & $6(1.3)$ & $4(1.0)$ & $2(6.2)$ & \\
\hline Balaenoptera borealis & $2(0.4)$ & $2(0.5)$ & $0(0.0)$ & \\
\hline Delphinus delphis & $51(11.3)$ & $47(11.2)$ & $4(12.5)$ & \\
\hline Globicephala macrorhynchus & $36(7.9)$ & $34(8.1)$ & $2(6.2)$ & \\
\hline Grampus griseus & $11(2.4)$ & $11(2.6)$ & $0(0.0)$ & \\
\hline Kogia breviceps & $23(5.1)$ & $23(5.5)$ & $0(0.0)$ & \\
\hline Mesoplodon densirostris & $7(1.5)$ & $7(1.7)$ & $0(0.0)$ & \\
\hline Mesoplodon europaeus & $6(1.3)$ & $5(1.2)$ & $1(3.1)$ & \\
\hline Orcinus orca & $1(0.2)$ & $1(0.2)$ & $0(0.0)$ & \\
\hline Phocoena phocoena & $1(0.2)$ & $1(0.2)$ & $0(0.0)$ & \\
\hline Physeter macrocephalus & $22(4.9)$ & $22(5.2)$ & $0(0.0)$ & \\
\hline Pseudorca crassidens & $2(0.4)$ & $2(0.5)$ & $0(0.0)$ & \\
\hline Stenella coeruleoalba & $92(20.3)$ & $86(20.4)$ & $6(18.8)$ & \\
\hline Stenella frontalis & 89 (19.6) & $74(17.6)$ & 15 (46.9) & \\
\hline Stenella longirostris & $3(0.7)$ & $3(0.7)$ & $0(0.0)$ & \\
\hline Neonate/calf & $131(28.9)$ & $123(29.2)$ & $8(25.0)$ & \\
\hline Juvenile/subadult & $130(28.7)$ & $120(28.5)$ & $10(31.2)$ & \\
\hline Adult & $192(42.4)$ & $178(42.3)$ & $14(43.8)$ & \\
\hline Coast & & & & 0.684 \\
\hline El Hierro y La Palma & $8(1.8)$ & $7(1.7)$ & $1(3.1)$ & \\
\hline La Gomera y Tenerife & $154(34.0)$ & $141(33.5)$ & $13(40.6)$ & \\
\hline Gran Canaria & $125(27.6)$ & $116(27.6)$ & $9(28.1)$ & \\
\hline Fuerteventura y Lanzarote & $166(36.6)$ & $157(37.3)$ & $9(28.1)$ & \\
\hline Mature categories & & & & 0.704 \\
\hline Immature & $225(50.1)$ & $210(50.4)$ & $15(46.9)$ & \\
\hline Mature & 224 (49.9) & 207 (49.6) & $17(53.1)$ & \\
\hline Body condition & & & & 0.004 \\
\hline Poor/very poor & $162(37.8)$ & $158(39.6)$ & $4(13.3)$ & \\
\hline Good/fair & $267(62.2)$ & $241(60.4)$ & $26(86.7)$ & \\
\hline Diving behavior & & & & 0.008 \\
\hline Shallow diver & 317 (70.0) & 288 (68.4) & 29 (90.6) & \\
\hline Deep diver & $136(30.0)$ & $133(31.6)$ & $3(9.4)$ & \\
\hline
\end{tabular}

The pathological cause of death in 453 cases was determined, among which, 32 cases were due to fishery interactions. 


\section{Body Condition}

Body condition could have been determined in $94.7 \%$ of the individuals, with a known cause of death (429/453). Most of the animals [62.2\% (267/429)] showed good/fair body condition, while $37.8 \%(162 / 429)$ were in poor/very poor body condition. The body condition of two dolphins, which died as a result of fishery interactions, could not have been determined owing to artifactual loss of tissue (case 9) and the very advanced state of decomposition of the carcass (code 5) (case 24) (Supplementary Table 1). Nonetheless, most dolphins showing signs of fishery interactions were in good/fair body condition $86.7 \%(26 / 30)$, compared with dolphins in poor/very poor condition. This difference was statistically significant $(p=0.004)$ (Table 3).

\section{Diving Behavior}

Shallow-water species were stranded in greater numbers, representing $70 \%$ of the animals with a known cause of death (317/453), while deep divers represented $30 \%$ of the cases (136/453). Although we observed more shallow than deep divers stranded during the study period, this difference was even larger when the prevalence of shallow [90.6\% (29/32)] vs. deep divers $[9.4 \%(3 / 32)]$ was compared with the findings of fishery interactions. This difference was statistically significant $(p=$ 0.008) (Table 3).

\section{Temporality of Stranding Events}

The yearly average number of stranding caused by fishery interactions was 1.7 animals (32 cases over 19 years), indicating a low rate of fishery interactions within the geographical area. In 2001 and 2017, a slight increase in the number of cases ( $n$ $=5$ each year) was noted. No fishery interactions were recorded during the years 2003, 2006, 2010, or 2011.

\section{DISCUSSION}

The rates of fishery interactions among cetaceans are underreported worldwide $(2,3)$. In the case of stranded cetaceans, an advanced decomposition code may hinder the determination of the cause of death. In addition, most fishery interaction findings (except gear cuts and impressions) are not pathognomonic $(4,5)$. Nonetheless, fisheries are considered a major global threat to cetaceans (34). Bycatch especially affects the harbor porpoise (Phocoena phocoena), bottlenose dolphin, common dolphin, and striped dolphin [e.g., (1, 35, 36)]. Furthermore, cases of chronic entanglements appear to be on the rise globally $(8,10)$, and their effects in certain baleen populations such as the minke whale is concerning (34).

In the Canary Islands, fishing is mainly artisanal and multispecific, and is characterized by the use of small vessels $(\leq 15 \mathrm{~m}$ in total length) and various types of fishing gear. Larger vessels are also used for tuna, but to a lesser extent ${ }^{2}$. Gillnets are allowed during certain periods in some designated areas, whereas trawling is absolutely forbidden in the archipelago. In addition, longlines and traps are forbidden in El Hierro and Fuerteventura,

${ }^{2}$ https://www.gobiernodecanarias.org/pesca/ as well as in all marine reserves of the archipelago [Annex 1. Decreto 182/2004 de 21 de diciembre, Reglamento de la Ley de Pesca de Canarias]. These conservative policies may explain the low annual rates of fishing-related deaths in cetaceans stranded along the Canary coasts.

Of the seven cetacean species identified, the Atlantic spotted dolphin was the most affected. This species, together with the Atlantic bottlenose dolphin, Gervais' beaked whale, short-finned pilot whale, and striped dolphin are regularly present year-round. Moreover, common dolphins and minke whales are seasonally present $(37,38)$.

\section{Bycatch}

Fishery interactions were likely recent and occurred close to the Canary coast in animals that were stranded alive or found dead in a fresh or very fresh state. Although local artisanal fisheries might have been responsible for these deaths, other fishing activities in international waters and illegal fishing cannot be ruled out. Until now, no pathognomonic clinical findings have been identified for bycaught animals (4). However, the greater the number of compatible lesions identified in a case, the more consistent the identification of bycatch $(5,39)$.

In this study, the ingestion of longline hooks affected Atlantic spotted dolphins alone $(n=5)$. Although this interaction with longline fisheries is well-known worldwide $(40,41)$, its related pathologies have been poorly reported. In this study, we identified two cases of Atlantic spotted dolphins with hooks that pierced the mandibles. To the best of our knowledge, this is also the first report of esophageal perforation with fibrinosuppurative pleuritis caused by hook ingestion in a dolphin species (Figure 2D). Although the literature reflects more information about larynx strangulation with longline fishing gear $(42,43)$, this type of lesions was not observed in the present study.

Different necropsy findings might be observed in cases of fishing net entrapment, depending on the fishery and the affected cetacean species $(5,21,22,44)$. Our results are consistent with those of Bernaldo de Quirós et al. (6), who reported external net marks, evidence of recent feeding (fresh undigested gastric contents), and disseminated intravascular gas bubbles.

In contrast with the findings of Bernaldo de Quirós et al. (6), only one case had reddish eyes (case 29), and another case had bubbles within the posterior chamber of the eye (case 23). In the present study, hyperinflated and hemorrhagic lungs were also identified, with occasional froth and rib impressions, corresponding histologically with areas of marked emphysema and alveolar edema. These findings agreed with those of Moore et al. (5). However, Bernaldo de Quirós et al. (6) found that froth in the airways and other lung changes (i.e., wet, heavy edema, congestion, and hemorrhage) were statistically poor indicators of bycatch.

In the present study, case 26 was one example of a bycaught dolphin with gas embolism. This animal exhibited a large number of gas bubbles (gas score of 18), consistent with the findings of Bernaldo de Quirós et al. (24). In addition, the composition of the gas bubbles was consistent with gases produced by compression and decompression, in which nitrogen is the main component, 
and $\mathrm{CO}_{2}$ can sometimes be present at high concentrations (20). Hydrogen, a marker of putrefaction, was found in the mesenteric veins alone, which is consistent with the findings of Bernaldo de Quirós et al. (24).

Pathological findings in cases of fishing net entrapment often suggest some degree of physical struggle associated with varying degrees of muscular exertion (5). In bycaught dolphins, the adrenocortical response and hyperthermia (45) induce injury to the skeletal muscle, similar to that described in live stranded cetaceans $(26,27,31)$. Acute degenerative changes have also been observed in severely polytraumatized free-ranging stranded cetaceans, such as in cases of ship strikes $(23,28)$ and fatal social traumatic intra-interspecific interactions $(23,32)$. Previous studies have reported cardiac changes $(29,46,47)$, as well as intracytoplasmic hepatocellular hyaline globules $(13,27,48)$ in agonal situations. Intravascular coagulation, mostly present in bycaught dolphins that endured aggression during handling, has been described in domestic animals with extensive tissue destruction (49). We also observed a few cases with mild inflammation of the CNS. These findings are consistent with the presence of concomitant infections.

\section{Chronic Entanglement}

It is difficult to know the actual number of entangled cetaceans even if the number of entangled individuals within a specific population is known, as the same animal can become entangled multiple times (50), and entangled carcasses tend to sink (8). Even with the limitations of the available data, the number of reported entanglements during the last decade is three times higher than that reported during the 1990 s, and $97 \%$ of those cases were entangled in fishing gear (10).

In the Atlantic Ocean, at least half of the mysticetes' deaths are caused by fishing gear (51). Minke whales particularly, appear to be less likely to survive entanglements than larger whales (52). The first description of an entangled minke whale in the Canary Islands was reported in 1993 in Morro Jable-Fuerteventura. This stranded animal was found dead, with a fishing net in the rostrum (53). In recent years (2012-2020), entanglements have included seven minke whales, six Bryde's whales (B. edeni), one humpback whale (Megaptera novaeangliae) ${ }^{3}$, two rough-toothed dolphins (Steno bredanensis), and one member of the Delphinidae family, sighted close to the Canary coasts (personal communication with the Canary Islands stranding network). Among these, three minke whales and two Bryde's whales were disentangled ${ }^{4}$. Whether those whales survived remains unknown, as no followup investigations were conducted after the disentanglement. Consistent with the findings of the present study, we consider chronic entanglements a potential threat to cetacean' populations in the Canary Islands, especially minke and Bryde's whales.

Entangled mysticetes are commonly found with ropes and nets within the oral cavity, or surrounding the flippers, or tail, and entangled odontocetes are usually found with recreational fishing gear, longlines, and fishing lures (5). Even if the gear

\footnotetext{
${ }^{3}$ https://twitter.com/GranCanariaCab/status/1209437122345734145

${ }^{4}$ https://www.eldiario.es/canariasahora/sociedad/Liberada-canarias-ballenaatrapada-marana_0_76292969.html
}

becomes detached, the scars of healed wounds may remain (54). In chronic entanglements, open and unhealed wounds could lead to septicemia and even death (5). Although no microbiological studies have been conducted on entangled cases in the present study, histological evaluation of the cases revealed intravascular coagulation, leukocytosis (mostly neutrophilic), and multiorgan hemorrhages in most of the affected animals.

In addition, those cases in poor body condition showed atrophy of the skeletal muscle. Case 19 also exhibited severe serous atrophy of pericardial fat, which indicates a catabolic condition. In the present study, only one animal was stranded alive and most cases showed mild degenerative changes in myocardiocytes. The occurrence of cardiac failure in cases of chronic entanglement should be further investigated. Similarly, the presence of hepatocellular hyaline globules in almost all cases was remarkable, previously described in agonal situations of stranded cetaceans $(27,48)$.

\section{Fisherman Aggression}

The predominance of artisanal fisheries in the Canary Islands suggests daily direct contact between cetaceans and fishermen, who are usually in small vessels a few meters above. Our results showed lethal trauma on the dorsal side of the dolphins, which is consistent with the fishermen's position just above, on the water's surface. Stabs and contusions affected mainly the thoracic cavity (with associated hemothorax, bone fractures, lung perforations), and/or the cephalic region (head contusions with associated brain hemorrhages). No other common findings were observed between these cases and the bycatch cases (e.g., net cuts/impressions on the skin, hyperinflated lungs, intravascular disseminated gas bubbles), nor evidence of being brought to deck. Although this category has been previously described, few cases have been reported $(7,55)$, because the most frequent aggressions inflicted by fishermen (amputations, stabs, and perforations) occur onboard, when animals are trapped in gillnets or trawlnets (5). Another form of human aggression is gunshot wounds (56), which were not observed in the present study. Histological findings, such as severe focal, extensive hemorrhages in the skin and muscles, and hemorrhagic lungs, agreed with the gross findings, which indicated that the various cases of trauma were inflicted while the animals were still alive. Histological findings were associated with agonal perimortem changes in dolphins, as well as systemic leukocytosis, due to open wounds.

\section{Statistical Analysis \\ Body Condition}

The body condition index is a good indirect indicator of the nutritional status of cetaceans (17). Previous studies have described bycaught dolphins in good body condition (4), but this is common in cetacean deaths due to the fatal trauma of ship strikes $(5,7,12,13)$, and social traumatic intra-interspecific interactions (32).

Our results indicate that individuals with good nutritional status may be more susceptible to adverse fishery interactions (especially bycatch), compared with animals exhibiting catabolic metabolism due to energy demanding pathologies (i.e., severe 
infections, parasitism, or neoplasia). In contrast, chronic entangled cetaceans typically appear in poor body condition $(5,7)$. Our results showed only a few necropsied cases of entanglement, only half of which showed poor-very poor body condition. However, observational records along the Canary coasts have confirmed the presence of entangled whales in poor body condition (personal communication with the Canary Islands stranding network).

\section{Diving Behavior}

In the present study, shallow diving species were affected by fishery interactions to a significantly greater extent than deep diving species. These findings are consistent with those of previous studies, in which the majority of the affected cetaceans were shallow-water species (5, 10, 40). In the Canary Islands, artisanal fishing activities are mainly pelagic and superficial $(0-150 \mathrm{~m}$ depth $)^{5}$, which is consistent with the swimming patterns of shallow species.

Nonetheless, it is important to highlight the fact that deep divers, especially sperm whales (Physeter macrocephalus), have been reported worldwide with considerable amounts of ingested marine debris, including fishing gear $(10,57,58)$. The Canary waters contain a great variety of deep divers, which are known to be affected by marine debris (59). We highly recommend more detailed descriptions of ingested foreign bodies, to better understand whether they originate from fishery activities.

\section{Temporality of Stranding Events}

Fortunately, our geographical area showed relatively low numbers of deaths due to fishing activities. This might be related to the sustainable artisanal fisheries and restrictive laws in the Canary waters. Similarly, in the Azores of Portugal, bycatch rates are low, with no evidence of any increase over the last 15 years (60). Artisanal fisheries cause a considerable number of deaths worldwide, even though these numbers are typically lower than those caused by industrial fisheries $(1,61)$.

In recent years, although sightings of live chronic entangled cetaceans have increased along the archipelago, necropsied cases remain scarce. The widespread use of social media to report the consequences of pollution in marine ecosystems has helped us to learn more about these interactions.

\section{CONCLUSIONS}

This is the first retrospective study of fishery interactions in stranded cetaceans along the Canary Islands. The determination of different types of fishery interactions as the cause of death was based on a 20-year investigation of stranded cetaceans. We described the most relevant gross and histologic findings in each type of interaction. Three types of fishery interactions were observed according to gross findings, including chronic entanglement, fisherman

${ }^{5}$ http://www.grancanariapescaenred.com/sobre-nosotros/como-pescamos/ aggression, and bycatch (longline hook ingestion and fishing net entrapment).

We found that the Atlantic spotted dolphin, regularly seen in our geographical area, was the most affected species. We also found that cetaceans in good-fair body condition and shallow-water species were significantly more affected. The low prevalence of fishery interactions in this region could be attributed to the broad protective legislation applicable to the Canary waters and the most prevalent type of fisheries, artisanal fisheries. However, there is increasing concern about chronic entanglements, especially in minke and Bryde's whales. We encourage continuous pathological studies on stranded cetaceans, to monitor fishing-related deaths and their consequences in cetacean populations. The findings of this study might contribute to the implementation of appropriate conservation policies in the Canary Islands.

\section{DATA AVAILABILITY STATEMENT}

All datasets generated for this study are included in the article/Supplementary Material.

\section{AUTHOR CONTRIBUTIONS}

RP-L, YB, MArb, AF, and ES: conceptualization. RP-L, AF, ES, JD, JD-D, SS, A, NG-Á, DZ, AX, MR, IF-J, FC, PD-S, SS-G, NC, CS$S$, MArr, YB, and MArb: sampling and diagnosis of the cause of death of each animal. PS, RP-L, and YB: data analyses. RP-L and MR: image editing. RP-L: writing. YB, MArb, MR, AF, and ES: supervision. All authors: review and editing.

\section{FUNDING}

We thank the Canary Islands Government for funding the stranding network. Partial funding came from the national project (ref. CGL2015-71498-P, PGC2018-101226-B-I00, $\mathrm{MAC} / 1.1 \mathrm{~b} / 149)$. The necropsies and sampling were done under permission from the Ministry of Agriculture, Fisheries, Food, and Environment of Spain. This study involved a Ph.D. (RP-L) and one postdoc (YB) fellowship supported by the University of Las Palmas de Gran Canaria.

\section{ACKNOWLEDGMENTS}

The authors would like to thank our laboratory technicians, all the members of the Cetacean Stranding Network of the Canary Islands, especially to Marisa Tejedor, Vidal Martín (Society for the Study of Cetaceans in the Canarian Archipelago) and Manuel Carrillo (Canary Islands Conservation).

\section{SUPPLEMENTARY MATERIAL}

The Supplementary Material for this article can be found online at: https://www.frontiersin.org/articles/10.3389/fvets. 2020.567258/full\#supplementary-material 


\section{REFERENCES}

1. Reeves RR, McClellan K, Werner TB. Marine mammal bycatch in gillnet and other entangling net fisheries, 1990 to 2011. Endanger Species Res. (2013) 20:71-97. doi: 10.3354/esr00481

2. Young NM, Iudicello S. Worldwide Bycatch of Cetaceans. U.S. Dep. Commerce, National Oceanic Atmospheric Administration Technical Memorandum, National Marine Fisheries Service NMFS-OPR-36 (2007). p. 276.

3. Dolman SJ, Moore MJ. Welfare implications of cetacean bycatch and entanglements. In: Marine Mammal Welfare. Cham: Springer (2017). p. 4165.

4. Kuiken T. Review of the criteria for the diagnosis of bycatch in cetaceans. In: Proceedings of the 2nd ECS Workshop on Cetacean Pathology. Saskatoon, SK: European Cetacean Society Newsletter 26 (Spec Issue) (1996). p. 38-43.

5. Moore MJ, Hoop J, Van Der Barco SG, Costidis AM, Gulland FM, Jepson PD, et al. Criteria and case definitions for serious injury and death of pinnipeds and cetaceans caused by anthropogenic trauma. Dis Aquat Organ. (2013) 103:229-64. doi: 10.3354/dao02566

6. Bernaldo de Quirós Y, Hartwick M, Rotstein DS, Garner MM, Bogomolni A, Greer W, et al. Discrimination between bycatch and other causes of cetacean and pinniped stranding. Dis Aquat Organ. (2018) 127:83-95. doi: 10.3354/dao03189

7. Read AJ, Murray KT. Gross Evidence of Human-Induced Mortality in Small Cetaceans. NOAA Technical Memorandum NMFS (2000). p. 21.

8. Laist DW. Impacts of marine debris: entanglement of marine life in marine debris, including a comprehensive list of species with entanglement. In: Coe JM, Rogers DB, editors. Marine Debris: Sources, Impacts, and Solutions. New York, NY: Springer-Verlag (1997). p. 99-139.

9. Macfadyen G. Huntington T, Cappell R. Abandoned, Lost or Otherwise Discarded Fishing Gear. Rome: Food and Agriculture Organization of the United Nations (2009).

10. Baulch S, Perry C. Evaluating the impacts of marine debris on cetaceans. Mar Pollut Bull. (2014) 80:210-21. doi: 10.1016/j.marpolbul.2013.12.050

11. IWC. Report of the Fourth Workshop on Large Whale Entanglement Issues. Provincetown: Center for Coastal Studies (2018). Available online at: https:// iwc.int/entanglement-response-experts-meet-in-provincetown

12. Arbelo M, Espinosa De Los Monteros A, Herráez P, Andrada M, Sierra E, Rodríguez F, et al. Pathology and causes of death of stranded cetaceans in the canary Islands (1999-2005). Dis Aquat Organ. (2013) 103:87-99. doi: $10.3354 /$ dao02558

13. Díaz-Delgado J, Fernández A, Sierra E, Sacchini S, Andrada M, Vela A, et al. Pathologic findings and causes of death of stranded cetaceans in the Canary Islands. PLoS ONE. (2018) 13:e0204444. doi: 10.1371/journal.pone. 0204444

14. Kuiken T, García-Hartmann M. Proceedings of dissection techniques and tissue sampling. In: Proceedings of the First ECS Workshop on Cetacean Pathology. Leiden (1991). p. 13-4.

15. Tejedor M. Aportaciones a la Osteología y sus Anomalías Asociadas en los Cetáceos Menores Del Archipiélago Canario. Las Palmas de Gran Canaria: University of Las Palmas de Gran Canaria (2016).

16. Geraci JR, Lounsbury VJ. Marine Mammals Ashore: A Field Guide for Strandings (N Aquarium, Ed.), 2 nd Edn. Baltimore, MD (2005).

17. Joblon MJ, Pokras MA, Morse B, Harry CT, Rose KS, Sharp SM, et al. Body condition scoring system for delphinids based on short-beaked common dolphins (Delphinus delphis). J Mar Anim Their Ecol. (2014) 7:5-13. Available online at: http://www.oers.ca/journal/volume7/issue2/scientific1.pdf

18. IJsseldijk LL, Brownlow AC, Mazzariol S. European Best Practice on Cetacean Post-Mortem Investigation and Tissue Sampling. Istanbul: Joint Accobams and Ascobans Document (2019).

19. Bernaldo de Quirós Y. Methodology and Analysis of Gas Embolism: Experimental Models and Stranded Cetaceans. Las Palmas de Gran Canaria: University of Las Palmas de Gran Canaria. (2011).

20. Bernaldo de Quirós Y, González-Díaz O, Møllerløkken A, Brubakk AO, Hjelde A, Saavedra P, et al. Differentiation at autopsy between in vivo gas embolism and putrefaction using gas composition analysis. Int J Legal Med. (2013) 127:437-45. doi: 10.1007/s00414-012-0783-6

21. Kuiken T, Simpson VR, Allchin CR, Bennett PM, Codd GA, Harris EA, et al. Mass mortality of common dolphins (Delphinus delphis) in south west
England due to incidental capture in fishing gear. Vet Rec. (1994) 134:81-9. doi: 10.1136/vr.134.4.81

22. Jepson PD, Deaville R, Acevedo-Whitehouse K, Barnett J, Brownlow A, Brownell RL, et al. What caused the UK's largest common dolphin (Delphinus delphis) mass stranding event? PLoS ONE. (2013) 8:e60953. doi: 10.1371/journal.pone.0060953

23. Sierra E, Espinosa de los Monteros A, Fernández A, Díaz-Delgado J, Suárez-Santana C, Arbelo $\mathrm{M}$, et al. Muscle pathology in free-ranging stranded cetaceans. Vet Pathol. (2017) 54:298-311. doi: 10.1177/03009858166 60747

24. Bernaldo de Quiros Y, Seewald JS, Sylva SP, Greer B, Niemeyer M, Bogomolni $\mathrm{AL}$, et al. Compositional discrimination of decompression and decomposition gas bubbles in bycaught seals and dolphins. PLoS ONE. (2013) 8:e83994. doi: 10.1371/journal.pone.0083994

25. Campbell-Malone R, Barco SG, Daoust P-Y, Knowlton AR, McLellan WA, Rotstein DS, et al. Gross and histologic evidence of sharp and blunt trauma in north atlantic right whales (Eubalaena glacialis) killed by vessels. J Zoo Wildl Med. (2008) 39:37-55. doi: 10.1638/2006-0057.1

26. Herráez P, Sierra E, Arbelo M, Jaber JR, de los Monteros AE, Fernández A. Rhabdomyolysis and myoglobinuric nephrosis (capture myopathy) in a striped dolphin. J Wildl Dis. (2007) 43:770-4. doi: 10.7589/0090-3558-4 3.4 .770

27. Herráez P, Espinosa de los Monteros A, Fernández A, Edwards JF, Sacchini S, Sierra E. Capture myopathy in live-stranded cetaceans. Vet J. (2013) 196:181-8. doi: 10.1016/j.tvj1.2012.09.021

28. Sierra E, Fernández A, Espinosa De Los Monteros A, Arbelo M, DíazDelgado J, Andrada M, et al. Histopathological muscle findings may be essential for a definitive diagnosis of suspected sharp trauma associated with ship strikes in stranded cetaceans. PLoS ONE. (2014) 9:e88780. doi: 10.1371/journal.pone.0088780

29. Câmara N, Sierra E, Fernandez-Maldonado C, Espinosa de Los Monteros A, Arbelo M, Fernandez A, et al. Stress cardiomyopathy in stranded cetaceans: a histological, histochemical and immunohistochemical study. Vet Rec. (2019) 185:694. doi: 10.1136/vr.105562

30. Câmara N, Sierra E, Fernández A, Suárez-santana CM, Puig-lozano R, Arbelo M, et al. Skeletal and cardiac rhabdomyolysis in a live-stranded neonatal Bryde's Whale with fetal distress. Front Vet Sci. (2019) 6:476. doi: $10.3389 /$ fvets.2019.00476

31. Câmara N, Sierra E, Fernández A, Arbelo M, Bernaldo de Quirós Y, Arregui M, et al. Capture myopathy and stress cardiomyopathy in a live-stranded Risso's Dolphin (Grampus griseus) in rehabilitation. Anim Open Access J MDPI. (2020) 10:220. doi: 10.3390/ani10020220

32. Puig-Lozano R, Fernández A, Saavedra P, Tejedor M, Sierra E, De la Fuente J, et al. Retrospective study of traumatic intra-interspecific interactions in stranded cetaceans, Canary Islands. Front Vet Sci. (2020) 7:107. doi: 10.3389/fvets.2020.00107

33. R Core Team. R: A Language and Environment for Statistical Computing. Vienna: R Foundation for Statistical Computing (2019). Available online at: https://www.R-project.org/

34. Dolman SJ, Brakes P. Sustainable fisheries management and the welfare of bycaught and entangled cetaceans. Front Vet Sci. (2018) 5:287. doi: 10.3389/fvets.2018.00287

35. Bjørge A, Skern-Mauritzen M, Rossman MC. Estimated bycatch of harbour porpoise (Phocoena phocoena) in two coastal gillnet fisheries in Norway, 2006-2008. Mitigation and implications for conservation. Biol Conserv. (2013) 161:164-73. doi: 10.1016/j.biocon.2013. 03.009

36. Peltier H, Authier M, Deaville R, Dabin W, Jepson PD, van Canneyt O, et al. Small cetacean bycatch as estimated from stranding schemes: the common dolphin case in the northeast Atlantic. Environ Sci Policy. (2016) 63:7-18. doi: 10.1016/j.envsci.2016.05.004

37. Martín V, Servidio A, Tejedor M, Arbelo M, Brederlau B, Neves S, et al. Cetaceans and conservation in the canary islands. In: 18th Biennial Conference on the Biology of Marine Mammals. Quebec City (2009).

38. Smit V, Ritter F, Ernert A, Strueh N. Habitat Partitioning by Cetaceans in a Multi-Species Ecosystem Around the Oceanic Island of La Gomera (Canary Islands). Stralsund: Poster communication presented at the Annual Conference of the ECS (2010). p. 12161. 
39. García Hartmann M, Couperus AS, Addink MJ. The diagnosis of bycatch: preliminary results of research in the Netherlands. Eur Cetacean Soc Newslett. (1994) 26:16-26.

40. NOAA. List-Fisheries-Summary-Tables. (2020). Available online atAvailable online at@ www.fisheries.noaa.gov

41. Werner TB, Northridge S, Press KM, Young N. Mitigating bycatch and depredation of marine mammals in longline fisheries. ICES J Mar Sci. (2015) 72:1576-86. doi: 10.1093/icesjms/fsv092

42. Gomerčić MD, Galov A, Gomerčić T, Škrtić D, Curković S, Lucić H, et al. Bottlenose dolphin (Tursiops truncatus) depredation resulting in larynx strangulation with gillnet parts. Mar Mammal Sci. (2009) 25:392-401. doi: 10.1111/j.1748-7692.2008.00259.x

43. Levy AM, Brenner O, Scheinln A, Morlck D, Ratner E, Goffman O, et al. Laryngeal snaring by ingested fishing net in a common Bottlenose Dolphin (Tursiops truncatus) off the israeli shoreline. J Wildl Dis. (2009) 45:834-8. doi: 10.7589/0090-3558-45.3.834

44. Deaville R, Jepson PD., (eds). CSIP Final Report for the period 1st January 2005-31st December 2010. London: Institute of Zoology (2011).

45. Curry BE. Stress in Mammals: The Potential Influence of Fishery-Induced Stress on Dolphins in the Eastern Tropical Pacific Ocean. La Jolla, CA: NOAA Technical Memorandum. NOAA-TM-NMFS-SWFSC-260 (1999).

46. Cowan DF, Curry BE. Histopathological Assessment of Dolphins Necropsies Onboard Vessels in the Eastern Tropical Pacific Tuna Fishery. Santa Cruz, CA: Southwest Fisheries Science Center, National Marine Fisheries Service, National Oceanographic and Atmospheric Administration (NOAA) Administrative Report No. LJ-02-24C (2002). p. 31.

47. Cowan DF, Curry BE. Histopathology of the alarm reaction in small odontocetes. J Comp Pathol. (2008) 139:24-33. doi: 10.1016/j.jcpa.2007.11.009

48. Jaber JR, Pérez J, Arbelo M, Andrada M, Hidalgo M, Gómez-Villamandos JC, et al. Hepatic lesions in cetaceans stranded in the Canary Islands. Vet Pathol. (2004) 41:147-53. doi: 10.1354/vp.41-2-147

49. Zachary JF. Bone marrow and blood cells. In: Zachary JF, editor. Pathologic Basis of Veterinary Disease. 6th ed. St. Louis, MI: Elsevier (2017). p. 724-61.

50. Knowlton AR, Hamilton PK, Marx MK, Pettis HM, Kraus SD. Monitoring North Atlantic right whale Eubalaena glacialis entanglement rates: a $30 \mathrm{yr}$ retrospective. Mar Ecol Prog Ser. (2012) 466:293-302. doi: 10.3354/meps09923

51. Northridge S, Cargill A, Smru AC, Mandleberg L, Hwdt SC, Sac BR. Entanglement of minke whales in Scottish waters; an investigation into occurrence, causes and mitigation. Contract Report. Final Report to Scottish Government CR/2007/49 (2010).

52. Lien J. Entrapments of large cetaceans in passive inshore fishing gear in Newfoundland and Labrador (1979-1990). Rep Int Whal Comm. (1994) 149-57.
53. van Waerebeek K, André M, Sequeira M, Vidal M, Daniel R, Anne C. Spatial and temporal distribution of the minke whale, Balaenoptera acutorostrata (Lacépède, 1804), in the southern. J Cetacean Res Manag. (1999) 1:223-37.

54. Heyning JE, Lewis TD. Entanglements of baleen whales in fishing gear off southern California. Rep Int Whal Comm. (1990) 40:427-31.

55. Byard RW, Kemper C, Bossley M, Kelly D, Hill M. Veterinary forensic pathology: the assessment of injuries to dolphins at postmortem. Forensic Pathol Rev. (2006) 4:415-33. doi: 10.1007/978-1-59259-921-9_14

56. Goldstein T, Johnson S, Phillips A, Hanni K, Fauquier D. Human-related injuries observed in live stranded pinnipeds along the. Aquat Mamm. (1999) 25:43-51.

57. Jacobsen JK, Massey L, Gulland F. Fatal ingestion of floating net debris by two sperm whales (Physeter macrocephalus). Mar Pollut Bull. (2010) 60:765-7. doi: 10.1016/j.marpolbul.2010.03.008

58. Unger B, Rebolledo ELB, Deaville R, Gröne A, IJsseldijk LL, Leopold MF, et al. Large amounts of marine debris found in sperm whales stranded along the North Sea coast in early 2016. Mar Pollut Bull. (2016) 112:134-41. doi: 10.1016/j.marpolbul.2016.08.027

59. Puig-Lozano R, Bernaldo de Quirós Y, Díaz-Delgado J, García-Álvarez N, Sierra E, De la Fuente J, et al. Retrospective study of foreign body-associated pathology in stranded cetaceans, Canary Islands (2000-2015). Environ Pollut. (2018) 243:519-27. doi: 10.1016/j.envpol.2018.09.012

60. Cruz MJJ, Machete M, Menezes G, Rogan E, Silva MAMA. Estimating common dolphin bycatch in the pole-and-line tuna fishery in the Azores. PeerJ. (2018) 2018:1-18. doi: 10.7717/peerj.4285

61. Mangel JC, Alfaro-Shigueto J, Waerebeek K, Van Cáceres C, Bearhop S, Witt MJ, et al. Small cetacean captures in Peruvian artisanal fisheries: high despite protective legislation. Biol Conserv. (2010) 143:136-43. doi: 10.1016/j.biocon.2009.09.017

Conflict of Interest: The authors declare that the research was conducted in the absence of any commercial or financial relationships that could be construed as a potential conflict of interest.

Copyright (C) 2020 Puig-Lozano, Fernández, Sierra, Saavedra, Suárez-Santana, De la Fuente, Díaz-Delgado, Godinho, García-Álvarez, Zucca, Xuriach, Arregui, Felipe-Jiménez, Consoli, Díaz-Santana, Segura-Göthlin, Câmara, Rivero, Sacchini, Bernaldo de Quirós and Arbelo. This is an open-access article distributed under the terms of the Creative Commons Attribution License (CC BY). The use, distribution or reproduction in other forums is permitted, provided the original author(s) and the copyright owner(s) are credited and that the original publication in this journal is cited, in accordance with accepted academic practice. No use, distribution or reproduction is permitted which does not comply with these terms. 